\title{
ESPR
}

\section{Invitation to apply for post as Treasurer of European Society of Paediatric Radiology}

(C) Springer-Verlag 2009

Applications are invited for the post of Treasurer to the European Society of Paediatric Radiology, as the post will be vacated early to enable Prof. Guy Sebag (the present incumbent) to concentrate on his duties as newly appointed European Managing Editor of our journal.

Interested applicants should have a working command of French and preferably a good knowledge of the French banking system as there is frequent detailed interaction with the Societé General Bank in Paris. The ESPR also employs an accountant with whom there is regular communication on financial matters.

The post will be filled initially on an acting basis, following provisional appointment by the officers of the ESPR, until approval at the ESPR AGM during the Bordeaux meeting in 2010. The successful applicant will be appointed for a total of 5 years.
Initially the appointee will work closely with Prof. Sebag for the duration of a handover period to be decided.

Interested parties are asked to send a letter ( or e-mail) of application detailing their relevant experience to:

Dr C.M. Owens

ESPR General Secretary

Consultant Radiologist

Department of Imaging

Great Ormond Street Hospital for Children

NHS Trust

Great Ormond Street

London WC1N 3JH, UK

e-mail: owensc@gosh.nhs.uk 